\title{
E-Governance Service System Readiness Assessment Framework from CSCW's Perspective
}

\author{
ASHRAF ALI WASEEM*, ZUBAIR AHMED SHAIKH**, AND AQEEL-UR-REHMAN*
}

RECEIVED ON 04.07.2017 ACCEPTED ON 12.02.2018

\begin{abstract}
Growing E-Participation services compel democratic governments to re-examine their E-Governance service system readiness assessment models with respect to their usability, effectiveness and participatory governance. In practice, the open government data, E-Participation initiatives, and their integration levels, are essential ingredients of E-Governance service systems. The debate about what constitutes EGovernance success, their quantifiable and qualitative variables, their divergent socio-technical dependencies, etc. is still on-going. E-Governance has emerged as a large-scale socio-technical and human centered problem space. We, therefore, assert that HCI (Human Computer Interaction) based system modeling and its supporting socio-technical tools and technologies can effectively be used to design and develop E-participatory governance systems. The research gap analysis highlights a stark paradox by showing a weak correlation between UN (United Nation) provided E-Participation Index and a perceived governance index. As a result, the authors in this paper propose an exclusive human centered and socio-technical design of E-GovSSRA (E-Governance Service System Readiness Assessment) framework by redefining E-Participation model in HCIs CSCW (Computer Supported Cooperative Work) perspective that aimed to present relatively strong correlation with a perceived governance index.
\end{abstract}

Key Words: E-Governance, E-Participation, Open Government, Connected Government, Human Computer Interaction, Computer Supported Cooperative Work.

\section{INTRODUCTION}

$\mathrm{E}$

-Participation is the practice by which citizens'

concerns, needs, and values are incorporated into corporate decision making [1] and thus can resolve most of the community problems [2]. It is agreed that E-Participation is flourishing in the countries where democracy is mature enough. If a democratic government wants to deliver, respect citizens' voice and trust, then it requires converting all public sector agencies from bureaucratic institutions to a more responsive and citizen participatory institutions, making them more open, accountable, trusted and transparent. UN also describes Good Governance as participatory, responsive, transparent, unbiased and accountable. Still an extensive study is required that can strongly associate Good Governance with E-Governance.

Authors E-Mail: (ashraf.waseem@hamdard.edu, zubair.shaikh@jinnah.edu, aqeel.rehman@hamdard.edu)

* Department of Computing, Faculty of Engineering Sciences \& Technology, Hamdard University, Karachi, Pakistan.

** Department of Computer Science, Muhammad Ali Jinnah University, Karachi,Pakistan.

This is an open access article published by Mehran University Research Journal of Engineering and Technology, Jamshoro under the CC by 4.0 International License. 
Whereas, E-Governance is understood to extend the scope of E-Government by adding E-Participation services in decision making and in policy making using the emerging and human centered technologies of social networking [3-6]. E-Participation sustainability is greatly dependent on organizational development and implementation of open and connected governments thus requiring a holistic engineering approach [7-9]. Hence, EGovernance is mostly about connectivity, connected people and connected systems; that is why E-Governance system has emerged as a large-scale, socio-technical and human centered problem space. We, therefore, assert that HCI based system modeling and it's supporting sociotechnical tools and technologies can effectively be used to design and develop E-participatory governance systems.

Waseem et. al. [10] elicited that E-Government can support transparency and accountability to some extent by providing online services directly to the citizens. If our main purpose is to combat corruption from public sector agencies by using participatory governance, then E-Participation services is the best tool to be inducted as a collective intelligence besides online service delivery of E-Government.

Waseem et. al. [10] also reviewed and analyzed literature from the key survey reports and articles on the theme of perceived E-Governance indexes and their measuring indicators. After testing the data of existing E-readiness and participatory indexes of their various editions specially the data of EGDI (E-Government Development Index) and EPI (E-Participation Index) provided by UN, it was found that their relevance with CPI(Corruption Perception Index), a perceived governance index, were not strong enough while EPI was more lagged behind in correlation with corruption control. The authors concluded that there is a need to improve existing measuring indicators of EpartM (E-Participation Maturity) model presented by United
Nation [11], and their weights to increase its relevance with perceived governance indexes. Thereby, design of an E-GovSSRA framework from HCI's CSCW perspective is required to make it strongly correlate with Good Governance.

To fill this gap, authors, in section 3 of this paper, are suggesting an enhanced and redefined E-PartM model in a collaborative workspace of $\mathrm{CSCW}$ and hence proposing a human-centered and a socio-technical design of E-GovSSRA framework for the development of interactive applications related to participatory governance and citizen-sourcing. This aims to improve the scores of existing E-Participation assessment index and thereby improves country's economy through efficient, accountable and transparent business processes and transactions.Finally, a relevant conclusion is drawn in section 4 , and the requirement of some case-specific toolkits is discussed as our future work in section 5. In this connection, the authors have also proposed a readiness assessment toolkit, for a continuing and an indigenous case-study associated to public procurements as a prototype implementation of E-GovSSRA framework.

\section{CSCW'S PERSPECTIVEOF E- GOVERNANCE}

E-Governance system is a class of interconnected subsystems. It has been emerged as a class of dynamic integrations of distributed, autonomous and heterogeneous systems with wide-ranging social, technical, humanistic, and environmental impacts. E-Participation in E-Governance system is referred to a group of humansworking in a social context to find innovative solutions collaboratively to achieve a common goal with the emerging features of sociotechnical tools and technologies of HCI that are used in

Mehran University Research Journal of Engineering \& Technology, Volume 38, No. 1, January, 2019 [p-ISSN: 0254-7821, e-ISSN: 2413-7219] 
CSCW. E-Governance system problem can therefore, be stated as a complex large-scale socio-technical cooperative system problem [13-15] that enables the recognition of collective intelligence in their business activities and in decision-making processes [16-17]. In this connection, we characterize the organization of E-Governance model and its performance measures in CSCW's perspective, preferably when working with socio-technical tools and technologies of social networking [18-20].

CSCW framework is providing a comprehensive collaborative workspace to support group working in the time and space coordinates [21]. It also characterizes tools and technologies used in its collaborative and pervasive environment as well as their psychological, organizational, and socio-technical impacts. It can encompass both the technical and social challenges encountered when supporting crowd sourcing [22-23]. Crowd sourcing is used to utilize the notion of human-computation for collecting and processing complex heterogeneous data to produce insight and actionable knowledge [24]. Thus for expressing participatory design as citizen sourcing, authors suggest that CSCW time/space groupware matrix is a useful notion to consider for a sociotechnical and human-centered design of E-Governance model.

\section{DISCUSSION FOR E-GovSSRA FRAMEWORK}

At this stage, the authors are able to discuss an E-GovSSRA framework and its components from CSCW's perspective.

\subsection{Measuring Indicators of E-GovSSRA Framework}

Researchers have so far captured several complex and multi faceted dimensions of governance and measured them on some predefined criteria.
We concentrate here only the ICT (Information and Communications Technology) specific key performance indicators of E-Governance environment. From research study and from our gap analyses and implications discussed in [10], it is revealed that E-Participation shall be the major indicator for E-GovSSRA framework while Open-Government and Connected-Government be its logical precursors for effective functioning of participatory governance system [25-27]. A detailed discussion on the influence of Open and Connected Government on E-Participation can be seen in section 3.1.2.

\subsubsection{E-Participation}

In most of the literature survey and in some well-known reports such as in [11,28-40], highlighting measuring indicators of participatory governance models, they endorsed that E-Participation of citizens has been making a direct influence on an E-Governance model besides other list of indicators related to its peripheral areas.

Now E-Participation is emerged as citizen-sourcing, agent a subset of crowd-sourcing, as citizens have rich knowledge in their concerns [41]. Citizens interact with authorities and groups, collaboratively and actively, using various E-Participation stages and their supporting tools and technologies [28].

As Government is advancing in ICT, the participation processes are easier to implement. The EC (European Commission) funded various E-Participation projects under the E-Participation readiness action. The setting up of ICT infrastructure, its connectivity, andthe latest development in social networking were the common features of the projects [18]. 
By the expansion in e-community, many researchers are relating E-Participation directly to E-democracy, focusing on $\mathrm{C}$ (Citizens) and $\mathrm{G}$ (Governments) as two major stakeholders in the E-democracy interaction processes.

The maturity of E-Participation stages is also crucial for maturity of E-Governance model. But, as it is demonstrated by Waseem et. al. [10], the potential of existing EParticipation maturity model provided by UN, up to the last edition [30], is still in its early stages of development. Thus there is a practical need to re-address the stages and their related performance measures of existing EParticipation maturity model(s).

\subsubsection{E-PartM Model}

Traditionally the stages of participation establish the levels of involvement to which the citizens engage in the process of E-Participation. Different topologies of E-Participation engagement levels are introduced, discussed and applied in general. After a comprehensive literature survey $[7,11,25,28,42-54]$, the authors are able to introduce an improved schema of E-Participation especially from CSCW's perspective of E-Governance. This schema of E-PartM model is mainly based on work discussed by Wimmer [49]; however, we acknowledge that some variations, in descriptions of these hierarchical stages, might be used. We call it a 4-staged application of E-PartM model. This is also discussed elementarily by Waseem et. al. [12]. The distinguished points of each stage of E-PartM model are discussed below:

(1) E-Informing: In Stage-1, the government agency is providing information in only one-way communication channel. The government information is accessible, as well as functions and processes are described here. Citizens can use search-engines for information retrieval and be able to download related documents and forms. In this stage, only limited data is available to the public. Here possible interaction is only $\{\mathrm{G} 2 \mathrm{C}\}$.

(2) E-Consulting: In Stage-2, citizens are allowed to send their feedbacks on issues of their interests in a one-way channel consultation without having online interactions. The agency assures data quality in terms of openness, accuracy, timeliness, and consistency in this stage. Here possible interactions are $\{\mathrm{G} 2 \mathrm{C}$ and $\mathrm{C} 2 \mathrm{G}\}$.

(3) E-Collaborating: In Stage-3, the citizens here can play active role in offering and suggesting policies in advanced two-way channel collaboration, but final authority of decision making is in the government hand. The citizens' ideas, common interests, knowledge, and expertise are crowd-sourced $\{\mathrm{C} 2 \mathrm{C}\}$ at this stage. Back-end automation of internal functions has to be redesigned for vertical integration of services. Here possible interactions are $\{\mathrm{G} 2 \mathrm{C}$, $\mathrm{C} 2 \mathrm{G}$, and $\mathrm{C} 2 \mathrm{C}$.

(4) E-Empowering: In Stage-4, the agency delegates transfer of power, influence, and policy making to the citizens, so the final decision is in the control of public hands. All distinct information and service systems are horizontally interconnected and interoperable $\{\mathrm{G} 2 \mathrm{G}\}$ so that citizens can get services easily at one single counter without going to an office. Here possible interactions are $\{\mathrm{G} 2 \mathrm{C}$, $\mathrm{C} 2 \mathrm{G}, \mathrm{C} 2 \mathrm{C}$, and $\mathrm{G} 2 \mathrm{G}\}$. 
The relationship between these stages shall have a logical sequence as in other related literature. Government agencies should pay attention on achieving one maturity level at a time and approaching it in an orderly manner, where lower levels must be all-inclusive.

We believe that in our proposed E-GovSSRA framework, these four stages of E-PartM model will form a more coherent and well-defined E-Participation initiatives by using HCI's CSCW groupware matrix of citizens' engagement that focuses on interactive, participatory, and collaborative citizen sourcing which is largely driven by the E-Governance directives and supported by emerging Web tools and technologies.

\subsubsection{Importance of Four Stages of E-PartM Model}

All E-Participation maturity models have one thing in common; they start with information level, followed by citizens' consultations, and end at the level where EParticipation really facilitates citizen's empowerment. Here the need for the four stages of E-PartM model is established by the following four implications:

By validating the four stages of E-PartM model, Wimmer [49] claimed that there should be an ecollaborating stage before e-empowering stage in the models mentioned by [52-53], to ensure that citizen sourcing can efficiently be provided in an advanced two-way communication.

(2) The UN, in its E-Government survey report-2016 [30], highlighted a prominent gap in percentage plygons, shown in between e-consultation and e-decision-making stages for the countries engaged in three stages of UN's EPI-16 index grouped by low to very high EPI rankings of countries as shown in Fig. 1. To fill this gap and to facilitate citizen sourcing in an advanced twoway communication, e-collaborating stage can effectively be inducted in between econsultation and e-decision-making stages of UN's EPI model. Most of the recent literatures, on E-Participation maturity models, are also suggesting that at least four stages of EParticipation are required to complete its maturity cycle smoothly.

(3) Waseem et. al. [10] highlighted in comparative analyses section that e-information stage of UN's EPI is unnecessarily presented as a single source of open government data. It can characteristically be bifurcated into two stages of passive-citizens' area to make it a total of 4 stages. So that high peak of e-information stage shall be normalized, as compare to other stages, at least from the analysis point of view.

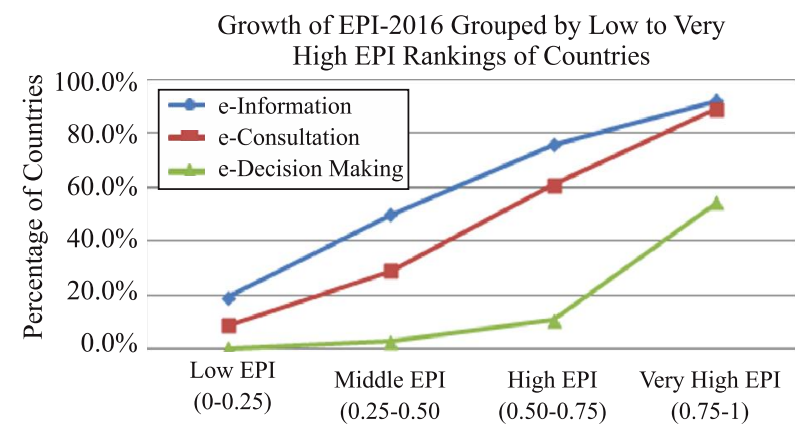

FIG. 1. HIGHLIGHTS PERCENTAGE POLYGONS OF COUNTRIES ENGAGED IN THREE STAGES OF EPI-16 GROUPED BY LOW TO VERY HIGH EPI RANKINGS OF COUNTRIES [30]

\begin{tabular}{|c|c|}
\hline Stage- 3 & Stage- 4 \\
$\{\mathrm{G} 2 \mathrm{C}, \mathrm{C} 2 \mathrm{G}, \mathrm{C} 2 \mathrm{C}\}$ & $\{\mathrm{G} 2 \mathrm{C}, \mathrm{C} 2 \mathrm{G}, \mathrm{C} 2 \mathrm{C}, \mathrm{G} 2 \mathrm{G}\}$ \\
E-Collaborating & E-Empowering \\
\hline Stage- 1 & Stage- 2 \\
$\{\mathrm{G} 2 \mathrm{C}\}$ & $\{\mathrm{G} 2 \mathrm{C}, \mathrm{C} 2 \mathrm{G}\}$ \\
E-Informing & E-Consulting \\
\hline
\end{tabular}

FIG. 2. SUPERIMPOSITION OF E-PATIM MODEL ON A 4STAGED GROUP OF INTERACTIONS OF STAKEHOLDERS AS A 4-QUADRANT MATRIX [12]

Mehran University Research Journal of Engineering \& Technology, Volume 38, No. 1, January, 2019 [p-ISSN: 0254-7821, e-ISSN: 2413-7219] 
(4) By efficiently fitting the four stages of E-PartM model on the prescribed $\mathrm{CSCW}$ time/space groupware matrix of citizens' engagements. The CSCW matrix implementation on E-Participation model can enhance the participatory processes and citizen sourcing among all groups of stakeholders using their supporting tools and technologies. The detailed discussion on this mapping is in section 3.1.1.4.

All these implications establish a concrete basis to induct an intermediate stage among the three stages of UN's E-Participation model that could help close the existing gaps thereby improving the scores of EParticipation index.

\subsubsection{Mapping E-PartM Model with Stakeholder's Group of Interactions}

Stakeholders are primarily the actors of initiatives. They play active role in their functions, for example, subjectmatter experts/representatives, target citizens, decisionmakers, etc. Waseem et. al. [12], have discussed two primary interactive stakeholders, which are distinguished in E-Governance concept as Citizenand Governmentitself, so that E-Governance readiness assessment plan can effectively be executed by their all possible 4-staged group of interactions that is $\mathrm{G} 2 \mathrm{C}, \mathrm{C} 2 \mathrm{G}, \mathrm{C} 2 \mathrm{C}$ and $\mathrm{G} 2 \mathrm{G}$. This is also acknowledged by Linders [9], presenting a typology for ICT-facilitated citizen coproduction initiatives.

Waseem et. al. [12], also suggested that E-PartM model, as elaborated in section 3.1.1.1 of this paper, can efficiently be superimposed on the 4-staged group of interactions of stakeholders as a 4-quadrant matrix shown in Fig. 2.
For validating a real time execution of our E-PartM model depicted in Fig. 2, a research based field survey was conducted to endorse our study in the following section.

\subsection{Results of Data Analysis of a Research Field Survey}

For validating our research study that the maturity of EParticipation servicing tools and techniques improves readiness of E-Governance service systems, a field survey was conducted, among 29 participants of officer's rank of 29 different government agencies of Pakistan, in a local context. Most of them were invited from federal agencies and as representatives of their departments. Remember that Pakistan is a country with strong diversity in opportunities, poverty indexes, literacy, justice, failing governance, and accountability. The survey was conducted in a two-day workshop organized by NIM (National Institute of Management) Karachi, Pakistan in June 2015; to find the stage-wise online participatory servicing tools offered to the public through website(s) of their respective departments for E-Governance initiatives. One of the questions asked to the participants of the field survey was: "What types of servicing tools and techniques are offered in your department's website(s) for E-Governance Service System Readiness Initiatives?" The data obtained is compiled inTable 1.

Survey Conclusion: Table 1 is showing that not any Eparticipatory servicing tool or technique is offered up to the $4^{\text {th }}$ stage of $\mathrm{G} 2 \mathrm{G}$ interaction in any of the government departments of Pakistan. Whereas, very limited tools or techniques of $\mathrm{C} 2 \mathrm{C}$ interactions of $3^{\text {rd }}$ stage with partial backend automation and limited online interactions between the stakeholders, are found in few of the

Mehran University Research Journal of Engineering \& Technology, Volume 38, No. 1, January, 2019 [p-ISSN: 0254-7821, e-ISSN: 2413-7219] 
E-Governance Service System Readiness Assessment Framework from CSCW's Perspective

TABLE 1. E-GOVERNANCE SERVICE SYSTEM READINESS INITIATIVES IN GOVT. DEPARTMENTS OF PAKISTAN

\begin{tabular}{|c|c|c|c|c|c|}
\hline \multirow[b]{2}{*}{ No. } & \multirow[b]{2}{*}{ Name of Department } & \multicolumn{4}{|c|}{ E-Governance Service System Readiness Initiatives } \\
\hline & & $\begin{array}{c}\text { Stage-1 } \\
(\mathrm{G} 2 \mathrm{C}) \\
\text { E-Informing }\end{array}$ & $\begin{array}{c}\text { Stage-2 } \\
\text { (C2G) } \\
\text { E-Consulting }\end{array}$ & $\begin{array}{c}\text { Stage-3 } \\
(\mathrm{C} 2 \mathrm{C}) \\
\text { E-Collaborating }\end{array}$ & $\begin{array}{c}\text { Stage-4 } \\
\text { (G2G) } \\
\text { E-Empowring }\end{array}$ \\
\hline 1. & Inland Revenue Serivce, FBR & $\checkmark$ & $\checkmark$ & - & - \\
\hline 2. & Customs, FBR & $\checkmark$ & $\checkmark$ & - & - \\
\hline 3. & Customs Service of Pakistan & $\checkmark$ & $\checkmark$ & - & - \\
\hline 4. & Police Service of Paksitan & $\checkmark$ & $\checkmark$ & - & - \\
\hline 5. & National Accountability Bureau & $\checkmark$ & $\checkmark$ & (Limited) & - \\
\hline 6. & Trade Development Authority of Pakistan & $\checkmark$ & $\checkmark$ & - & - \\
\hline 7. & Health & $\checkmark$ & $\checkmark$ & - & - \\
\hline 8. & Immigration and Passport & $\checkmark$ & $\checkmark$ & (Limited) & - \\
\hline 9. & Irrigation & $\checkmark$ & (Limited) & - & - \\
\hline 10. & Establishment Division & $\checkmark$ & - & - & - \\
\hline 11. & Eelection Commission of Pakistan & $\checkmark$ & $\checkmark$ & (Limited) & - \\
\hline 12. & Federal Investigation Agency & $\checkmark$ & $\checkmark$ & (Limited) & - \\
\hline 13. & Criminal Prosecution Service, Law & $\checkmark$ & $\checkmark$ & - & - \\
\hline 14. & Excise and Texation & $\checkmark$ & $\checkmark$ & - & - \\
\hline 15. & Pakistan Ordinance Factory & $\checkmark$ & $\checkmark$ & - & - \\
\hline 16. & Auditor General of Pakistan & $\checkmark$ & - & - & - \\
\hline 17. & S\&GAD, Balochistan & $\checkmark$ & - & - & - \\
\hline 18. & Overseas Pakistanis Welfare Division & $\checkmark$ & (Limited) & - & - \\
\hline 19. & Planning Commission of Pakistan & $\checkmark$ & (Limited) & - & - \\
\hline 20. & National Disaster Management Authority & $\checkmark$ & $\checkmark$ & (Limited) & - \\
\hline 21. & Thar Coal Energy Board, Sindh & (Limited) & - & - & - \\
\hline 22. & Zulfiqarabad Development Authority, Sindh & - & - & - & - \\
\hline 23. & Sindh Technical Education ad Vocational Traing Authority & $\checkmark$ & $\checkmark$ & - & - \\
\hline 24. & Sindh Public Procurement Regulatory Authority & $\checkmark$ & $\checkmark$ & - & - \\
\hline 25. & Pakistan Railways & $\checkmark$ & $\checkmark$ & - & - \\
\hline 26. & Senate of Pakistan & $\checkmark$ & (Limited) & - & - \\
\hline 27. & Ministry of Parliamentary Affairs & $\checkmark$ & (Limited) & - & - \\
\hline 28. & Sports and Youth Affairs & (Limited) & - & - & - \\
\hline 29. & Zakat, Azad Jammu \& Kashmir & - & - & - & - \\
\hline
\end{tabular}

Mehran University Research Journal of Engineering \& Technology, Volume 38, No. 1, January, 2019 [p-ISSN: 0254-7821, e-ISSN: 2413-7219] 
departments. Most of the agencies are offering basic information about their departments as the stage- 1 of G2C interactions and to some extent consultation is carried out as stage- 2 of $\mathrm{C} 2 \mathrm{G}$ interactions. This verifies that the potential for online participatory servicing tools and techniques is still in its early stages of maturity in the countries with weak governance. Secondly, the total score of the departments for each stage of E-PartM model is declining in the order from lower to higher stage; however, this is true for some better-case countries as well. Certainly, this ratio will improve smoothly for best performing countries.

The developed countries, those are good in EGovernance initiatives are also playing well in all stages of E-Participation [55]. Hence, it is found that EParticipation services up to the last maturity stage are essential for a total readiness of E-Governance service systems.

\subsubsection{Mapping E-PartM Model with CSCW Groupware Matrix}

The expansion in e-community, through the use of Web 2.0, Web 3.0 and so on, seeks to optimize E-Participation by enhancing collaboration among the systems of stakeholders [56]. This raises the inspiration for creating socially enabled and human centered processes of citizensourcing in order to engage a broader community, known as a crowd-ware, in the creation of awareness and involvement on the process outcomes of E-Governance [57]. Whereas, the crowd-ware members as compare to groupware members share or do not share some kind of interest, collaborate even if unconsciously, may or may not know each other, but are interested in a common context [58]. Schneider et. al. [58] also defined crowdware as a class of systems for supporting virtual and real crowds, inheriting the main components of groupware matrix of CSCW, along with Web 2.0 and Cloud Computing, in order to provide advanced services anywhere and anytime, connecting individuals in heterogeneous environments.

Thus CSCW time/space groupware matrix is an effective approach to consider for expressing participatory crowdworking, escaping time and space limits by using emerging socio-technical tools and technologies. The classical time/ space groupware matrix of $\mathrm{CSCW}$, re-presented by [59],is depicted in Fig. 3.

Whereas the proposed 4-stages of E-PartM model, illustrated in Fig. 2, are the participatory stages to support crowds in carrying out their works, breaking down time and space barriers, by using the stage-wise web supporting tools and technologies. On the other hand, the web tools on each quadrant of CSCW also show those technical and collaborative tools of $\mathrm{CSCW}$, which are found suitable to create interfaces for citizens to obtain services corresponding to each stage of E-PartM model; hence it can be mapped to each time/space quadrant respectively. It helps the government in collecting the wisdom of the crowds, so that citizens can participate in various functions and processes of government. Thus EPartM model can efficiently be superimposed on the groupware (crowd-ware) matrix of CSCW illustrated in Fig. 3 is re-presented in Fig. 4.

The interaction of stakeholders is also extending in this framework as we move along the stages of E-Participation from one-way to multi-way channel consultation that is from $\mathrm{G} 2 \mathrm{C}$ to $\mathrm{G} 2 \mathrm{G}$

It has been observed that the job of citizen (C) is also varying during E-Participation stages, from passive

Mehran University Research Journal of Engineering \& Technology, Volume 38, No. 1, January, 2019 [p-ISSN: 0254-7821, e-ISSN: 2413-7219] 
information consumer to active decision-maker [25,33].

Hence the 4-stages of E-Participation can efficiently be divided into Passive and Active Participation areas as represented in Fig. 5, categorized as:

Passive Citizens Area: E-Informing \& E-Consulting, and

Active Citizens Area: E-Collaborating \& E-Empowering.

Further discussion about the framework is in section 3.2.

\subsubsection{Influence of Open and Connected Government on E-Participation}

Open Government requires maturity of OGD (Open Government Data) policies and regulations as prerequisite performance measures of E-Participation [9,25].OGD also brings up challenges of data accuracy, data protection and privacy concerns [31]. Other instruments are also desired to support effective public accountability, such as well-defined code of conduct, effective supreme audit institutions, human resource development, etc. [30].
Whereas, Connected Government requires maturity of ICT-infrastructure, connectivity, ICT usage, and other likewise indicators for backend automation and process re-engineering of various interoperable systems of government agencies [26,30,39,55,60]. The concept of connected government is derived from the whole-ofgovernment approach that is centralizing the entry point of service delivery to a single portal where citizens can access all government-supplied information and services ubiquitously, regardless of which government agency provides them.

To validate the relationship of E-Participation with Open Government and Connected Government, we analyzed here following two applicable indexes, latest so far, to find any significant correlation with a currently available EPI-16 provided by UN [30].

(1) ODB(Open Data Barometer) 2015 [31], which is, in our context, better example of describing Open Government Data index.

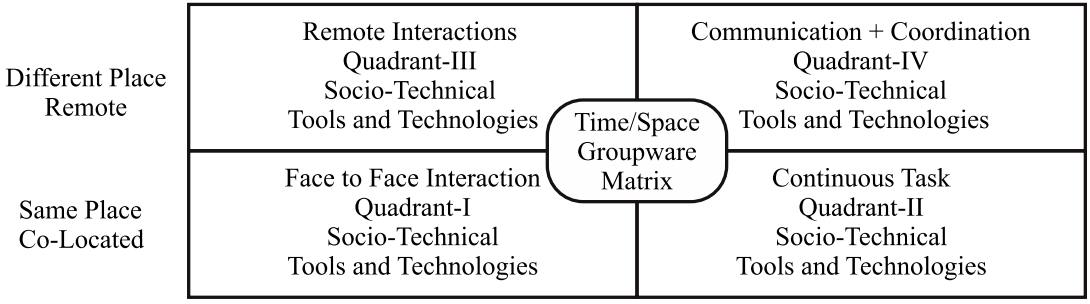

Same Time Synchronous

Different Time Asynchronous

FIG. 3. TIME/SPACE GROUPWARE MATRIX OF CSCW

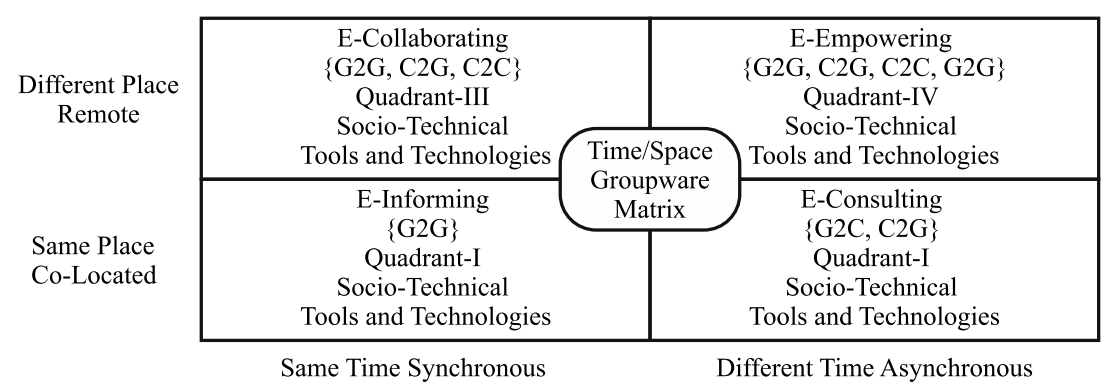

FIG. 4. SUPERIMPOSITION OF FIG. 2 AND FIG. 3 
(2) ITUIDI (International Telecommunication UnitICT Development Index) 2016 [60], which is, in our context, better example of describing Connected Government Data index.

Table 2 shows that EPI-16 is strongly correlated with ODB15 and ITUIDI-16. This supports our study that EParticipation is strongly associated with Open Government and Connected Government. Thus we are considering here Open Government and Connected Government as precursors for initiating E-PartM model.

Open Government initiatives promote E-Participation services in relatively preliminary interactive
communications.Lee and Kwak [25] said, it mainly depends on expressive social media tools and technologies to connect people and help share their ideas so that citizens can play here only passive roles. Connected Government initiatives, on the other hand, promote E-Participation services in composite tasks or projects that seek to co-create specific results [61] using advanced two way real time communications. It relies on collaborative social media tools and technologies so that citizens can play active roles here [25].

By finalizing E-Participation road map, depicted in Fig. 5, it is logically suggested that Open Government initiatives can be well synchronized with the first two stages of E-

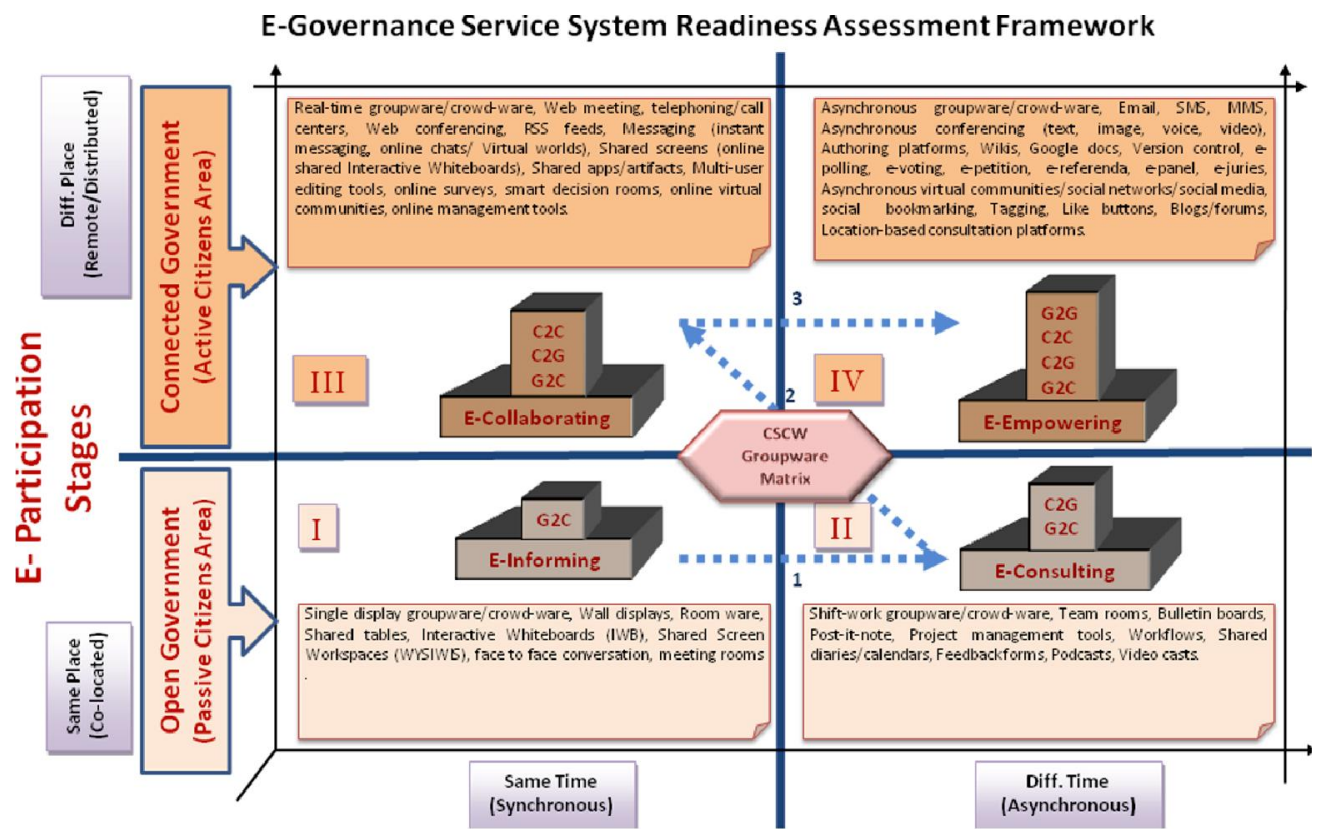

FIG. 5. E-GOVERNANCE SERVICE SYSTEM READINESS ASSESSMENT FRAMWORK

TABLE 2. ILLUSTRATE CORRELATION BETWEEN EPI-16 \& ODB-15, AND BETWEEN EPI-16 AND ITUIDI-16

\begin{tabular}{|c|c|c|}
\hline & ODB-15 & ITUIDI-16 \\
\hline EPI-16 & $\mathrm{r}=0.804 * 0.797^{*}$ \\
\hline Correlation & Strong Positive & Strong Positive \\
\hline \multicolumn{2}{|c|}{$*$ Correlation is Significant at the 0.01 Level (2-Tailed) } \\
\hline
\end{tabular}

Mehran University Research Journal of Engineering \& Technology, Volume 38, No. 1, January, 2019 [p-ISSN: 0254-7821, e-ISSN: 2413-7219] 
PartM model, whereas Connected Government initiatives are effectively mapped with the last two stages of maturity model. Hence, E-Participation of a country will increase only if it's Open and Connected Governments initiatives are increasing.

\subsection{Design of E-Gov SSRA Framework}

The diagrammatic representation of all this discussion on E-GovSSRA framework is illustrated in Fig. 5.

In Fig. 5, the four stages of E-Participation are efficiently superimposed on the Time/Space groupware matrix of CSCW. The text boxes on each quadrant shows those supported tools and technologies [43,44,46,62], which are found suitable to create interfaces for the stakeholders to obtain E-Participation services corresponding to each stage in its collaborative workspace. By associating these tools along with EParticipation road map, the authors group some selected tools that can efficiently be used in the first stage $\{\mathrm{E}$ informing \} so as to share information related to policy making initiatives sponsored by the government. In the second stage $\{$ E-consulting\}, the authors group those tools and technologies that can allow citizens' consultations on diverse topic(s) defined by the government. As a result, first two stages would approach Open Government maturity. Finally, in the last two stages \{E-collaborating and E-empowering\}, the authors group those tools and technologies that can support stakeholders in their common interests to collaborate with each other $\{\mathrm{C} 2 \mathrm{C}$ and $\mathrm{G} 2 \mathrm{G}\}$ in crowd sourcing, policy formulation, knowledge base, decision making processes, etc. That would be obtained through multichannel service delivery tools and real time integrated services, hence approaching a Connected Government maturity.
Researchers are continuously investigating on these tools to promote creative citizen-sourcing and participation activities.Because of changing nature of organizations' work, researchers often have complexity to decide which set(s) of tools will help a particular group. Therefore, the set of tools depicted in Fig. 5 are overlapping and nonexhaustive.

On the other hand, the precursors Open and Connected Governments are labeled with passive and active citizens' areas respectively. They are approaching their maturity stages as we move from left to right stage of their respective areas of E-Participation road-map shaded with different colors. The maturity stage of E-Participation is achieved only if the maturity stages of Open and Connected Governments are achieved in a sequence. Recall that EParticipation stages progress in ascending order of maturity levels by evaluating readiness of any agency or country. We cannot skip any intermediate stage to jump to the next stage of maturity.

Next the four stages of E-Participation, its precursors Open Government and Connected Government should be further investigated for their sub indicators and their weight analyses in the light of existing literature to increase the efficacy of E-Governance. Such evaluations need further investigation on country-specific diagnostic data and case studies to discover the relevant constraints on governance issues for a particular country circumstances. For this purpose, the authors have proposed a readiness assessment toolkit [12] for a continuing and indigenous case-study associated to the procurements of public sector agencies in one of the province of Pakistan. The toolkit can efficiently be served as a prototype implementation of proposed EGovSSRA framework.

Mehran University Research Journal of Engineering \& Technology, Volume 38, No. 1, January, 2019 [p-ISSN: 0254-7821, e-ISSN: 2413-7219] 
The authors hope that the proposed human centered design of E-GovSSRA framework using HCI's CSCW perspective will extend the relationship of EParticipation and HCI with E-Governance; and will help to spotlight within the research community as how to best asses the real-life complex problem of EGovernance readiness system that could lead to one of the most vibrant and notable streams of literature in the field.

\section{CONCLUSION}

We have reviewed and analyzed literature from the key survey reports and articles on the theme of E-Governance and its measuring indicators. By analyzing their development tendencies, it is emerged that major defining indicator for E-Governance is found to be E-Participation in providing public voice, openness, increasing transparency and governance in public sector agencies thereby controlling corruption through the human centered and socio-technical environment of EGovernance system, while Open Government and Connected Government appeared as its ICT-based supporting indicators.

To increase the performance of governments in participatory governance, in this paper, a socio-technical and participatory E-GovSSRA framework is proposed by redefining E-PartM model in CSCW's perspective. The authors believe that it may increase not only the effectiveness of E-Participation stages by fitting it on a CSCW's groupware matrix of crowd sourcing but also could help close the existing gaps. It may also increase its correlation with good governance in view of CSCW's supporting socio-technical tools and technologies of its collaborative workspace.
We should note that the purpose of this paper does not provide an exhaustive review of E-Participation theories, methods, and possibly tools and technologies nor it covered the complete scope of human cognitive analyses of such domain. Indeed, our key contribution is to suggest a participatory E-Governance model by using the strength of CSCW framework so as to promote a socio-technical approach for the development of interactive applications related to participatory governance.

\section{FUTURE WORK}

In order to test the scalability, usability and reliability issues of E-GovSSRA framework, some more set of readiness assessment toolkits or case tools, consisting of some related E-Participation servicing tools and techniques, are needed. The test data shall be collected from these specially designed toolkits. It can be used as government servicing web tools of the country specific case-studies. Such toolkits are needed to address the:

(i) Scalability issues ranging from demonstrational prototypes to real-size applications of the EGovSSRA framework.

(ii) Usability issues by using usability-evaluationmethods for tracking any structural problem in the framework.

(iii) Reliability issues to find ways to guarantee the correct functioning of the framework. Actions such as verification, validation, and exhaustive testing are possible ways to address this problem.

This will enable us to refine the framework, if needed, by reducing or removing the identified problems and obtain more accurate results thereof. 


\section{ACKNOWLEDGEMENT}

Acknowledgment and gratitude have to be given to the UN research staff, Transparency International and other likewise organizations such as ITU, and WWWF, whose surveyed data, statistics, indexes and their measuring indicators are made available and helpful for our research study and analyses.

\section{REFERENCES}

[1] Creighton, J.L., "The Public Participation Handbook: Making Better Decisions through Citizen Involvement", John Wiley \& Sons, 2005.

[2] Fischer, F., "Citizen Participation and the Democratization of Policy Expertise: From Theoretical Inquiry to Practical Cases", Policy Sciences, Volume 26, No. 3, pp. 165-187, Switzerland, 1993.

[3] Van Dijk, J., "Digital Democracy: Vision and Reality", Innovation and the Public Sector, Volume 19, pp. 49-62, IOS Press, Netherlands, 2012.

[4] Chadwick, A., "Web 2.0: New Challenges for the Study of E-Democracy in an Era of Informational Exuberance", ISJLP, Volume 5, pp. 9, California, USA, 2008.

[5] Waller, S.N., "Engaging Citizens in State Recreation Planning: Best Practices from Oregon", Public Manager, Volume 38, No. 4, pp. 72, USA, 2009.

[6] Vedel, T., "The Idea of Electronic Democracy: Origins, Visions and Questions", Parliamentary Affairs, Volume 59, No. 2, pp. 226-235, Oxford Academic, UK, 2006 .

[7] Medimorec, D., Parycek, P., and Schossböck, J., "Vitalizing Democracy through E-Participation and Open Government: An Austrian and Eastern European Perspective", Bertelsmann-Stiftung.Org Publishing, 2010 .
[8] Scherer, S., and Wimmer, M.A., "Reference Framework for E-Participation Projects", Proceedings of International Conference on Electronic Participation, pp. 145-156, Springer, 2011.

[9] Linders, D., "From E-Government to We-Government: Defining a Typology for Citizen Coproduction in the Age of Social Media", Government Information Quarterly, Volume 29, No. 4, pp. 446-454, Netherlands, 2012.

[10] Waseem, A.A., Shaikh, Z.A., andRehman, A., "Impact of E-Participation Index on Perceived Governance Index: A Need for Redefining E-Participation Model", Romanian Journal of Information Science and Technology, Romania, 2017.

[11] Hafeez, S., and Sher, S.W., "UN Global E-Government Readiness Report 2005: From E-Government to EInclusion", United Nations Publications, 2006.

[12] Waseem, A.A., Shaikh, Z.A., and Rehman, A., "A Toolkit for Prototype Implementation of E-Governance Service System Readiness Assessment Framework," Proceedings of International Conference on HCI in Business, Government and Organizations, pp. 259-270, Springer, 2016.

[13] Sussman, J., Dodder, R., McConnell, J.B., Mostashari, A., and Sgouridis, S., "The CLIOS Process: AUser's Guide", Frameworks and Models in Engineering Systems, pp. 12, 2007.

[14] Clarke, L.A., Osterweil, L.J., and Avrunin, G.S., "Supporting Human-Intensive Systems", Proceedings of FSE/SDP Workshop on Future of Software Engineering Research, ACM, pp. 87-92, 2010.

[15] Skopik, F., Schall, D., and Dustdar, S., "Discovering and Managing Social Compositions in Collaborative Enterprise Crowdsourcing Systems", International Journal of Cooperative Information Systems, Volume 21, No. 4, pp. 297-341, USA, 2012.

[16] Ludwig, T., Reuter, C., Siebigteroth, T., and Pipek, V., "Crowdmonitor: Mobile Crowd Sensing for Assessing Physical and Digital Activities of Citizens during Emergencies", Proceedings of 33rd Annual ACM Conference on Human Factors in Computing Systems, pp. 4083-4092, 2015. 
[17] Nunes, F., Verdezoto, N., Fitzpatrick, G., Kyng, M., Grönvall, E., and Storni, C., "Self-Care Technologies in HCI: Trends, Tensions, and Opportunities", ACM Transactions on Computer-Human Interaction, Volume 22, No. 6, pp. 33, New York, USA, 2015.

[18] Lacigova, O., Maizite, A., and Cave, B., "eParticipation and Social Media: A Symbiotic Relationship", European Journal of ePractice, Volume 16, pp. 71-76, Barcelona, 2012 .

[19] McGrath, K., Elbanna, A., Hercheui, M., Panagiotopoulos, P., and Saad, E., "Exploring the Democratic Potential of Online Social Networking: The Scope and Limitations of e-Participation", Association for Information Systems, USA, 2012.

[20] Soon, C., and Soh, Y.D., "Engagement@ Web 2.0 between the Government and Citizens in Singapore: Dialogic Communication on Facebook?," Asian Journal of Communication, Volume 24, No. 1, pp. 42-59, UK, 2014

[21] Hewett, T., Baecker, R., Card, S., Carey, T., Gasen, J., Mantei, M., Perlman, G., Strong, G., and Verplank, W., "ACM SIGCHI Curricula for Human-Computer Interaction", ACM SIGCHI, 1996.

[22] Kittur, A., Nickerson, J.V., Bernstein, M., Gerber, E., Shaw, A., Zimmerman, J., Lease, M., and Horton, J., "The Future of Crowd Work", Proceedings of ACM Conference on Computer Supported Cooperative Work, pp. 1301-1318, 2013.

[23] Jacko, J.A., "Human Computer Interaction Handbook: Fundamentals, Evolving Technologies, and Emerging Applications", CRC Press, 2012.

[24] Basharat, A., Arpinar, I.B., Dastgheib, S., Kursuncu, U., Kochut, K., and Dogdu, E., "Semantically Enriched Task and Workflow Automation in Crowdsourcing for Linked Data Management", International Journal of Semantic Computing, Volume 8, No. 4, pp. 415-439, USA, 2014.

[25] Lee, G., and Kwak, Y.H., "An Open Government Maturity Model for Social Media-Based Public Engagement", Government Information Quarterly, Volume 29, No. 4, pp. 492-503, Netherlands, 2012.
[26] Bertot, J.C., Jaeger, P.T., and Grimes, J.M., "Using ICTs to Create a Culture of Transparency: E-Government and Social Media as Openness and Anti-Corruption Tools for Societies", Government Information Quarterly, Volume 27, No. 3, pp. 264-271, Netherlands, 2010.

[27] Ndou, V., "E-Government for Developing Countries: Opportunities and Challenges", The Electronic Journal of Information Systems in Developing Countries, Volume 18, China, 2004.

[28] You, L., Motta, G., Liu, K., and Ma, T., "CITY FEED: A Pilot System of Citizen-Sourcing for City Issue Management", ACM Transactions on Intelligent Systems and Technology, Volume 7, No. 4, pp. 53, New York, USA, 2016.

[29] Transparency International., "Corruption Perceptions Index 2016", Transparency International, Germany, 2016.

[30] UNDESA (United Nations E-Government Survey), "EGovernment in Support of Sustainable Development", UN Publishing Section, New York, 2016.

[31] WWWF, "Open Data Barometer Global Report", 3rd Edition., World Wide Web Foundation, 2015.

[32] Davies, T., Sharif, R., and Alonso, J., "Open Data Barometer Global Report”, 2nd Edition., World Wide Web Foundation, 2014.

[33] UNDESA (United Nations E-Government Survey),"EGovernment for the Future We Want", UN Publishing Section, New York, 2014.

[34] Davies, T., "Open Data Barometer, Global Report", 1st Edition., World Wide Web Foundation, 2013.

[35] Pérez-Espés, C., Jiménez, J.M.M., and Wimmer, M.A., "Evaluating the Efficacy of E-Participation Experiences", Proceedings of EGOV/ePart Ongoing Research, pp. 250-257, 2013.

[36] UNDESA (United Nations E-government Survey),"EGovernment for the People", UN Publishing Section, New York, 2012. 
[37] Kaufmann, D., Kraay, A., and Mastruzzi, M., “The Worldwide Governance Indicators: Methodology and Analytical Issues", Hague Journal on the Rule of Law, Volume 3, No. 2, pp. 220-246, Heidelberg, Germany, 2011 .

[38] UNDESA (United Nations E-Government Survey), "Leveraging E-Government at a Time of Financial and Economic Crisis", 9211231833 , Volume 2, UN Publishing Section, New York, 2010.

[39] Chen, Y.C., and Hsieh, J.Y., "Advancing E Governance: Comparing Taiwan and the United States", Public Administration Review, Volume 69, No. 1, pp. S151-S158, USA, 2009.

[40] Holzer, M., and Kim, S.-T., "Digital Governance in Municipalities Worldwide: A Longitudinal Assessment of Municipal Websites throughout the World", United Nations, USA, 2007.

[41] Greengard, S., "Following the Crowd", Communications of the ACM, Volume 54, No. 2, pp. 20-22, New York, USA, 2011.

[42] Motta, G., You, L., Sacco, D., and Ma, T., "City Feed: A Crowdsourcing System for City Governance", Proceedings of 8 th IEEE International Symposium on Service Oriented System Engineering, pp. 439-445, 2014 .

[43] Al-Dalou, R., and Abu-Shanab, E., "E-Participation Levels and Technologies", Proceedings of 6th International Conference on Information Technology, pp. 8-10, 2013.

[44] Abu-Shanab, E., and Al-Dalou, R., "E-Participation Initiatives: A Framework for Technical Tools", Proceedings of International Arab Conference of eTechnology, pp. 57-64, 2012.

[45] Gatautis, R., "Creating Public Value through eParticipation: Wave Project", Economics \& Management, Kaunas, Lithuania, 2010.

[46] Sobaci, Z., "What the Turkish Parliamentary Web Site Offers to Citizens in Terms of e-Participation: A Content Analysis", Information Polity, Volume 15, No. 3, pp. 227-241, IOS Press, Netherlands, 2010.
IAP2,"IAP2 Public Participation Spectrum", IAP2, URL: http://www.iap2.org/as sociations/4748/files/ spectrum.pdf, 2007.

[48] Tambouris, E., Liotas, N., and Tarabanis, K., "A Framework for Assessing eParticipation Projects and Tools", Proceedings of 40th IEEE Annual Hawaii International Conference on System Sciences, pp. 90-90, 2007.

[49] Wimmer, M.A., "Ontology for an e-Participation Virtual Resource Centre", Proceedings of ACM $1^{\text {st }}$ International Conference on Theory and Practice of Electronic Governance, pp. 89-98, 2007.

[50] Ahmed, N., "An Overview of e-Participation Models", Proceedings of UNDESA Workshop on E-Participation and E-Government: Understanding the Present and Creating the Future”, pp. 27-28, Budapest, Hungary, 2006 .

[51] Lukensmeyer, C.J., and Torres, L.H., "Public Deliberation: A Manager's Guide to Citizen Engagement", IBM Center for the Business of Government, 2006.

[52] Macintosh, A., "Characterizing e-Participation in PolicyMaking", Proceedings of IEEE 37 th Annual Hawaii International Conference on System Sciences, pp. 10, 2004.

[53] Gramberger, M., "Citizens as Partners: OECD Handbook on Information, Consultation and Public Participation in Policy Making”, Organisation for Economic Cooperation and Development, 2001.

[54] Porwol, L., Ojo, A., and Breslin, J., "Structuring eParticipation Perspectives: Mapping and Aligning Models to Core Facets", Proceedings of ACM 14th Annual International Conference on Digital Government Research, pp. 224-234, 2013.

[55] Phang, C.W., and Kankanhalli, A., "A Framework of ICT Exploitation for e-Participation Initiatives", ACM Communications, Volume 51, No. 12, pp. 128-132, New York, USA, 2008.

[56] Shelton, T., "Business Models for the Social Mobile Cloud: Transform Your Business Using Social Media, Mobile Internet, and Cloud Computing”, John Wiley \& Sons, 2013. 
[57] Brambilla, M., Fraternali, P., and Vaca Ruiz, C.K., "Combining Social Web and BPM for Improving Enterprise Performances: The BPM4 People Approach to Social BPM", Proceedings of ACM 21 st International Conference on World Wide Web, pp. 223-226, 2012.

[58] Schneider, D., Moraes, K., De Souza, J.M., and Esteves, M.G.P., "CSCWD: Five Characters in Search of Crowds", Proceedings of IEEE 16th International Conference on Computer Supported Cooperative Work in Design, pp. 634-641, 2012.

[59] Baecker, R.M., "Readings in Human-Computer Interaction: Toward the Year 2000", Morgan Kaufmann, 2014
[60] ITU, "Measuring the Information Society Report", International Telecommunications Union, 2016.

[61] Bovaird, T., "Beyond Engagement and Participation: User and Community Coproduction of Public Services", Public Administration Review, Volume 67, No. 5, pp. 846-860, USA, 2007.

[62] Fedotova, O., Teixeira, L., and Alvelos, H., "EParticipation in Portugal: Evaluation of Government Electronic Platforms", Procedia Technology, Volume 5, pp. 152-161, Netherlands, 2012. 